\title{
Opinions on the Political Economy of the New Turkish Healthcare System
}

\author{
Prof. Dr. Aysegül Kaptanoğlu (Trakya University, Turkey)
}

\begin{abstract}
Turkish health care system is going on health care transitions nowadays. Fundamental role of government in providing, financing and managing public services, including health care are changed. Health care marketers insist that competition and aggressive management will raise health care productivity. Health economist suggests that health is a public service and has a value. The Health Care System in Turkey is financed by public funds, compulsory insurance premiums and delivered $(90 \%)$ by The Ministry of Health $(\mathrm{MoH})$ that also manages the system. For the sustainability of universal access to health care special insurance programs according the rule of political economy should be built. Poor and severe ill people who cannot work and elderly may not get access to public medical insurance. So, for contributing to the nationwide public health care system rich people could give some extra insurance premium and obtain additional private insurance as well. Referral chain might be established in the country in between primary, secondary and tertiary care.
\end{abstract}

\section{Introduction}

The purpose of this article is to draw up a brief global picture of political health economy in Turkey. In order to understand what is going on Turkish Health care system, there is a need for closer look to the context. Turkish Ministry of Health has initiated the Health Transition Program. "Health Transformation Programme" launched by the Turkish Government in 2003. Structural deficiencies of health care system were universal health insurance, access and quality of healthcare services for all citizens in needs, the strong establishment of the Primary Health Care Network via family practice. By this way the role of the Ministry of Health, change of the legislative environment, autonomy of healthcare facilities, capacity building and health professional training, health information systems as well as drug and medical devices independent control institutions. Turkey has 44 JCI certified hospitals, approximately 100 internationally standardized private hospitals and more than 1000 Turkish Republic Ministry of Health accredited hospitals with 60 university hospitals (Karadeniz. 2012). The Health Care System in Turkey is financed by public funds, compulsory insurance premiums and delivered $(90 \%)$ by The Ministry of Health $(\mathrm{MoH})$ that also manages the system. Healthcare providers are classified as physician, dentist, nurse, health officer, midwife and pharmacist etc. There is not a referral chain in the country yet.

Transformation in Health Care in Turkey has 4 major components. (Sharma, 2013).

1) Prime based general health insurance,

2) Determining the role Ministry of Health as overall planning, coordination and evaluation.

3) Solo practice of primary care by contracted family doctors.

4) Change of payment schedule for health care staff (fee for per capita + fee for service).

Until 2013 health indicators have improved, as observed in Table 1.

\begin{tabular}{|l|l|l|l|l|l|l|}
\hline Indicators & 1960 & 1980 & 1990 & 2000 & 2005 & $2013^{* *}$ \\
\hline Population (million) & 27,7 & 44,7 & 56,4 & 67,8 & 73,2 & 79,0 \\
\hline Infant mortality rate (\%) & $>150$ & 126 & 67 & 28.9 & 23.6 & 18.5 \\
\hline Total fertility rate (births per woman) & $>4$ & 3.41 & 2.65 & 2.27 & 2.19 & 2.07 \\
\hline Life expectancy at birth (year) & $<60$ & 61.9 & 66.3 & 70.4 & 71.3 & 72.3 \\
\hline Population per hospital bed & $>500$ & 451 & 469 & 391 & 374 & 336 \\
\hline Population per physician & 2,799 & 1,631 & 1,109 & 792 & 715 & 658 \\
\hline
\end{tabular}

Table 1. Changes of some selected health indicators Source: Turkish Statistical Institute database and 9th strategic development plan report

Health care is an important component of an economy. Health care technologies have advanced rapidly in the past few decades and the demand for health care continues to grow, health care expenditures have been increasing steadily in industrialized nations (Eatwell, J., Milgate, M. and Newman, P. (eds) 1987). In the Turkey, for example, health care expenditures as a share of the gross national product (GNP) grew from 4.4 percent in 1970 to 6.7 percent in 2009

\section{Definition of Political Economy}

The "political economy is the science of wealth" and "deals with efforts made by man to supply wants and satisfy desires". The political economy of health care has complex procedures (Hart, 2008). 


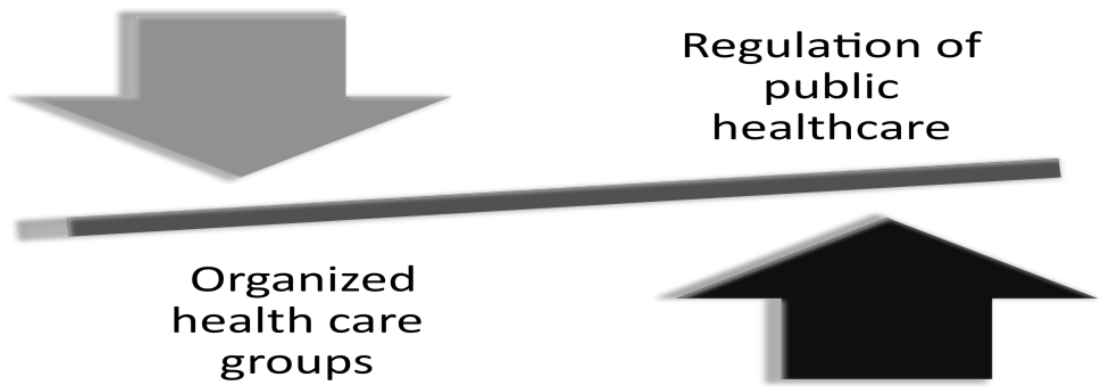

Figure 1. The political economy

Efficiency and equity of heath care services to be the main concern of political economy. Political economy is the study of the role of economic processes in transforming society (Campos, Rafael, 2011). This economy makes extensive and intensive use of important analysis in making sense of society and history. This branch of economy does not deal with the context of political, cultural, and environmental processes, as well as other economic processes (Devi, Ngaire 2013).

\section{Measuring Health Care System}

The health care system gain can be measured by healthier births, lives, and improved patient's health etc. The most important result of the health care system is health gain that can be measured by quality of life (qaly) per year. Qaly is able to combine 'the effects of health interventions on mortality and morbidity into a single index'. This single index might provide a 'common currency' for comparisons across different chronic illness and health intervention. For example Qaly is calculated as follow:

Patient A has a serious, life-threatening condition like Leukemia.

If he continues receiving usual standard treatment A will live for 1 year. The quality of life of A will be 0.5 ( 0 or below $=$ worst possible health, $1=$ best possible health)

If A receives the new drug, A will live for 2 year with a quality of life of 0.7 .

The new treatment is compared with standard care in terms of the Qaly's gained:

Standard treatment: 1 (year's extra life) x $0.5=0.5$ QALY

New treatment: 2 x $0.6=1.2$ Qaly

Therefore, the new treatment leads to 0.7 additional Qaly's (that is: 1.2 -0.5 Qaly $=0.7$ Qaly's).

The cost of the new drug is assumed to be $£ 5,000$, standard treatment costs $£ 2000$.

The treatment costs of leukaemia (£3000) are divided by the Qaly’s gained (1.2) for calculating the cost per Qaly. So the new treatment would cost $£ 2500$ per Qaly. The well-organised political economy for health care system including whole population can help to sustain good mortality.

\section{Political Economy Created by Turkish Health Care System}

In 2003, the health transformation project started to be implemented. One of the main goals of this project was to increase accessibility to health care services. According to the results of this project, health expenditures increased rapidly. It was 3.86 of GDP in 2004. It reached $5.13 \%$ of GDP in 2009. Financing of healthcare led to a decrease in direct out-of-pocket expenditures (OOP) and the private health sector that expand all over the big cities. According to the current official data from the $\mathrm{MoH}$, the level of OOP has fallen to $16.7 \%$. According to the Ministry of Health's review (2012), the total health financing was at $7.4 \%$ levels. This trend shows that public spending and resource allocation on medical costs in relations to income has caused major concerns over the social and economic consequences to an increasingly larger segment of the population. The health service availability has been improved. The population has a big increase in hospital utilization. In times of illness, lowincome families are not trying to find money for needed treatments in case if they paid some amount like 30-90 Turkish Lira monthly. All family member spouse or husband can profit within this amount of money. 


\section{Health Insurance in Turkish Health Care System}

The compulsory health insurance system in Turkey was firstly introduced in 2012 to cover all citizens. Government officials, state employees and staff of large invested companies are paying according to their wages. Their insurance covers all family member like spouse and mother, father. Those considered indigents such as war heroes, war invalids and all children below the age 18 are paid by government funds. Today, about 20 million Turkish who are not poor or disable are uninsured. Those people do not work anywhere else. Expanding insurance coverage is planned to reduce OOP payments, but most studies have found only a modest effect. The design of current insurance schemes has made the poor paying hospital fees for the rich and extracts insurance refunds from poor provinces to wealthier cities. It is state officials and urban elites that are the main beneficiaries of the insurance refunds as insurance coverage and refunds are to cover mainly high-class curative care and inpatient services in urban and centralized hospitals.

The health insurance refund system is facing major challenges in containing costs, involving dysfunctional rules and informal arrangements in which corruption incurs. There is hardly any effective mechanism to record, report or measure service costs and adverse insurance selections. Neither can they control doctors in their prescriptions and consultations involving duplication and falsification of doctors' medical records to claim refunds and medical reimbursements. Furthermore, pharmaceutical companies can lobby, or often pay bribes, to make their drugs included in insurance lists. Once on the lists, they encourage physicians to overprescribe expensive medications and laboratory tests.

\section{Management and Productivity in Primary Care}

Everyone in Turkey has a free access to a family practice center functioning as a personal physician. Currently, there is not a compulsory referral system in Turkey. $\mathrm{MoH}$ points to the inadequate number of primary care physicians for not being able to initiate referral chain obligation. An efficient gatekeeper role is needed for an effective primary care in the country. In 2013, Turkey has 1.7 physicians and 1.4 nurses per 1000 people. There is a serious demand of health staff for primary care health services. Clinical productivity of primary care has not been taken seriously until yet. There have been successive revisions designed to encourage proactive work considered by government likely to raise outputs of health care and to shift responsibilities for ambulant care from hospital outpatient departments back to primary care, particularly for continuing care of chronic health conditions like COPD, diabetes, hypertension etc. MoH of Turkey had been concerned almost exclusively with satisfying users rather than verifiably improving either their health, the health of their communities or their efficiency as gatekeepers to hospital based specialists. Everyone had free access to go secondary and tertiary care for undifferentiated, unprioritised public wants. Therefore, iatrogenic risks could not be avoided. The economic consequences of its loss in Turkey need to be calculated. Hospital based specialists are seen as a good doctor in the form of public opinion. Patients do not trust primary care physicians. They only apply to primary care whenever they need to repeat their prescriptions. Another main reason of application is oblige physician to write false illness report. Media side also report that primary care physician knowledge and health service is insufficient.

\section{Management and Productivity in Hospital Based Care}

Health services create jobs. This is increasingly labor intensive rather than capital intensive. The expansion of this work area depends in large part on further developing the skills of its workforce. If health care expands, it means that everyone wins economically. In recent years, mostly machines replaced agriculture and manufacture sectors instead of human labor. But, productivity labor in health care would still depend on increasingly very sophisticated human skills. Patients act as a co-producers rather than clients. As a result the health sector is expected to grow gradually every year. Health professionals would become relatively more costly to employ. In the very near future spending on health care in hospital would rise. The cost of health care is attributable to wages. If physicians are paid by capitation, they want to keep their patients as customers.

\section{Conclusion}

Healthcare systems are in crisis worldwide with rising rates of diseases and a growing gap between the poor and rich. The modern healthcare systems focus on benefitting individuals rather than communities (Ren, 2013). According to the rule of liberalism private healthcare is supported to provide quality healthcare only to those who can afford it. Budgetary cuts generally come at the expense of the primary determinants of health. Political economic gains are focused on the short-term healthcare system.

Pharmaceutical industry, medical profession unions, World banking institutions and political decision makers, think tank institutions challenged neoliberal assumptions directly to prevent the medical profession, health economists and public health practitioners in some instances (Sarbo, 2013). Financial support for health care would become a predominant consideration in the Turkish health system in near future. Turkey has adopted 
blended payment systems that consist of a salary-like base supplemented by incentive payments with revolving funds. These payment reforms would not lead to the recreation of a "gatekeeper" system. Patients would continue to access to hospital based specialists. For the sustainability of universal access health care special insurance programs according the rule of political economy must be done. Poor people, severe ill people who cannot work and elderly may not get access to public medical insurance. For redistributive reasons, the rich who contribute to the nationwide public health care system could give some extra insurance premium and obtain additional private insurance as well. The aim of Turkish's health reforms is to ensure all citizen s access to general health care in case if they regularly pay the insurance premiums according to their income (especially the informal economy). Tertiary care physicians might select patients who need extra health care services like diseases. Process indicators might audit those physicians. To solve the political health economic insurance problem actions might be taken by health care providers, patients (consumers), policy makers, and health care industry. The important mater is that public health economic source is for health profit of all citizens of nations (Idrissa, 2013). The political economy of health in Turkey faces several challenges. Ageing population has a moderate challenge to long-term financial sustainability. The major challenges is linked to the labor market and weaknesses in resource allocation, purchasing and provider payment. Strengthening health care-financing policy can address many of the inefficiencies in resource allocation and health care utilization that exacerbate cost pressures.

\section{References}

- Campos, SP, Rafael GM, 2011. Estudios Multidisciplinarios sobre Derecho Medico y Organizaciones de la Salud. Uruguay: La Ley Uruguay,

- Devi S., Ngaire W. (2013) Trojan Multilateralism: Global Cooperation on Health, GEG Working Paper 72.

- Eatwell, J., Milgate, M. and Newman, P. (eds) 1987. The New Palgrave. A Dictionary of Economics, London, Macmillan, Vol. IV. 907.

- Forsberg, Le Thanh. 2013. The Political Economy of Healthcare Commercialization in Vietnam. GEG Working Paper 2013/74.

- Gloppen, Siri. 2009. "Litigation as a Strategy to Hold Governments Accountable for Implementing the Right to Health." Health and Human Rights. 10 (2) 21-36.

- Hart JT. 2008. The political economy of health care. A clinical perspective. The policy press. United Kingdom. 256-258.

- Idrissa, A. 2013. Out of the Penkelemes: The ECOWAS Project as Transformation. GEG Working Paper 2013/76.

- Karadeniz O. 2012 Extension of Health Services Coverage for Needy in Turkey: From Social Assistance to General. Health Insurance. Journal of Social Security / 2Idrissa, Abdourahmane. 2013. Divided Commitments: UEMOA, the Franc Zone, and ECOWAS. GEG Working Paper 2013/77.

- Ren, H. 2013. Enterprise Hegemony and Embedded Hierarchy Network: The Political Economy and Process of Global Compact Governance in China. GEG Working Paper 2013/73.

- Sarbo DN. 2013. Reconceptualizing Regional Integration in Africa: The European Model and Africa's Priorities. GEG Working Paper 2013/78.

- Sharma, P. 2013. Role of Rules and Relations in Global Trade Governance. GEG Working Paper 2013/75.

- $\quad$ http://socialcapital.weebly.com/uploads/1/0/5/9/1059736/woolcock_paper.pdf. Last Visited 01.06.2013.

- $\quad$ http://www.sup.org.uy/Boletines/BolNov2011.pdf. Last Visited 01.06.2013

- http://www.shef.ac.uk/polopoly_fs/1.209843!/file/serps_2012020.pdf. Last Visited 01.06.2013.

- http://www.who.int/countryfocus/cooperation_strategy/ccsbrief_tur_en.pdf Last Visited 01.06.2013.

- http://www.oecd.org/els/health-systems/oecdhealthdata2012-frequentlyrequesteddata.htm. Last Visited 01.06.2013.

- http://siteresources.worldbank.org/INTTURKEY/Resources/361616-1173282369589/tr_per_cr.pdf. Last Visited 01.06.2013. 